\title{
Intensive Faculty-led International Multicultural Courses: Understanding the Perceptions from Students and Improving the Quality of Course Delivery by Faculty
}

\author{
Dorota Celinska $^{1}$, Roberto Swazo ${ }^{2}$ \\ ${ }^{1}$ Roosevelt University, Chicago, Illinois, USA \\ ${ }^{2}$ University of Northern Iowa, Cedar Falls, Iowa, USA \\ Correspondence: Dorota Celinska, College of Education, Roosevelt University, 18 S. Michigan Avenue, Chicago, IL, \\ 60603, USA
}

Received: May 10, 2015 Accepted: May 25, 2015 Online Published: June 3, 2015

doi:10.11114/jets.v3i4.813 URL: http://dx.doi.org/10.11114/jets.v3i4.813

\begin{abstract}
Graduate programs in counselor education have historically offered the on campus multicultural course to increase students' diversity knowledge, skills, and cultural self-awareness in order to satisfy state, national and international accreditation mandates. This article analyzes the self-reported perceptions and experiences of 21 master's level counselor education students who participated in an intensive faculty-led international course (IFLIC) as an alternative format to the traditional on campus multicultural course. The pedagogy and curriculum of the IFLIC format is cemented on current multicultural international methodologies of instruction. Subsequently, it presents an in-depth analysis of students' perceptions of their acquisition of multicultural concepts and skills, as well the role of the course's curricular and instructional components in their multicultural learning outcomes. It offers a set of recommendations based on the research findings for academic/educational/faculty developers in higher education with the ultimate goal of improving the quality of international higher education. And, it provides delivery strategies for international programs seeking effective implementation of short-term faculty-led international courses (IFLIC).
\end{abstract}

Keywords: faculty-led international courses, multicultural course development

\section{Introduction}

\subsection{Introduce the Problem}

In compliance with state, national, and international accreditation standards, programs in counselor education have integrated multicultural training as a vital curricular element (Council for Accreditation of Counseling and Related Educational Programs, 2009; Estrada, Durlak, \& Juarez, 2002; Kerl, 2002). Although the literature and the accreditation bodies established that multicultural training is critical for the development of professional counselors, the effectiveness of multicultural training pedagogy remains a challenge, especially at the international level.

\subsection{Explore Importance of the Problem}

The traditional multicultural on campus course has been embraced as a vehicle to increase the multicultural competencies in counselor education. However, due to the complexities of the multicultural content and because it transcends the walls of the classroom into societal and personal realms, there is a consensus that even though it meets all the professional criteria, this course design has severe limitations (Coleman, 2006; Collins \& Pieterse, 2007; Stebnicki \& Cubero, 2008). For example, the literature advocates that across disciplines students are more engaged in learning through experiential learning compared to the traditional didactic model in the classroom (Alexander, Krucek, \& Ponterotto, 2005; Chen, Jones, \& Moreland, 2014).

\subsection{Describe Relevant Scholarship}

\subsubsection{Community Service Learning}

The community service learning (CSL) approach has been seen as an alternative to traditional on campus courses with the intent to increase the awareness of students' personal cultural constructs and to promote empathy towards diverse populations (Collins \& Pieterse, 2007). Aside of focusing on knowledge, skills, and awareness which are the primary 
domains of multicultural competence, in CSL students must pay attention to their own personal growth (Arthur \& Achenbach, 2002; Rowell \& Benshoff, 2008). One variation of service learning is the international service learning (ISL) that combines the traditional academic instruction with the community-based services in an international context. Programs offering such opportunities have proliferated across the U.S.A. and internationally across academic disciplines (Annette, 2003; Bringle \& Tonkin, 2004; Kiely, 2011).

\subsubsection{International Service Learning}

According to Crabtree and Sapp (2009), international service learning (ISL) seeks to connect international travel, education, and community service to augment the students' worldwide awareness, create intercultural empathy, and improve civic awareness and skills. International service learning experiences have been successful at promoting global and civic awareness as well as intercultural empathy at the short-term level (Parker \& Dautoff, 2007). In a classical stance on the future of international service learning activities, Amir (1969) predicted that a well-designed set of ISL activities can achieve learning outcomes that encompass powerful psychological, emotional, ideological, and cultural-self disruptions with the purpose of increasing cross-cultural awareness and reducing ethnocentrism. However, several research studies have indicated that the success of these international encounters depends on a variety of variables such as group status, gender, the sojourner's country of origin, individual predisposition and attitudes, and unique elements of the host country (Amir \& Garti, 1977; Baty \& Dold, 1977; Kim, 1995; Ibrahim, 2012).

\subsection{State Hypotheses and Their Correspondence to Research Design}

The intensive faculty-led international course (IFLIC) is based on the principle of substantial and intentional culture immersion in which students do not have an option but to engage themselves in a new environment that forces them to evaluate their own cultural identities and worldviews. The IFLIC is designed to operate within a framework of 10-20 days as opposed to study abroad experiences that span from one academic semester to a full year abroad. The IFLIC typically involves international service learning activities that have as a goal the development of empathy and cultural exchanges (Swazo \& Celinska, 2014). Before embarking into a faculty-led international course, academic programs must have a sound theoretical and pedagogical foundation to frame their multicultural initiatives. The authors postulate that in a well-designed IFLIC model that is enriched by international service learning activities, both the students and community members are empowered and benefited through reciprocal relationships. The following are the theoretical premises that served as the pedagogical foundation of this study's intensive faculty-led international course:

(1) Dialoguing, reading, and lecturing promote the acquisition of intellectual knowledge but may not translate into personal and professional transformation. Emotional and behavioral growth must be pursued in addition to the acquisition of skills and knowledge, preferably via structured, guided experiential learning.

(2) Cultural growth and personal development are intertwined because all humans are cultural beings regardless of whether or not they have an ethnic memory connecting them to their ancestors. This phenomenon is especially palpable among populations from the Americas in which cultural, ethnic, and racial integration is emphasized to conform to a generic and distinctive sociocultural norm from the new host country. As a result, a substantial number of students come to multicultural courses unprepared to articulate their identity beyond the generic labels of ethnicity/race (e.g. European descent, African American Hispanic/Latino, or Native indigenous). The phenomena of sociocultural isolation and ethnocentrism are experienced by many populations regardless of country or continent of origin. Consequently, cultural and personal development is equally important to all individuals regardless of the country or continent of origin (Swazo, 2013).

(3) The lack of second language knowledge and minimal cultural competence are highlighted to parallel the experience of immigrants with the intent of promoting empathy. Linguistic dissonance and discomfort are progressively and strategically provoked in order to trigger an internal reaction leading to self-evaluation and emotional change.

(4) The "us" versus "them" paradigm is discouraged and replaced by the creation of a knowledge-bridge between students and local community members. Both parties should equally benefit as a result of these intercultural exchanges.

(5) Prevention of cultural imposition in interactions within local communities is imperative. The "missionary" or "peace corps" approach is replaced by the utilization of students' expertise as a vital resource and empowerment vehicle to local communities but always considering the community's background, experiences, and culture. An organic process of learning and sharing is presented instead of imposition.

(6) The "guilt trip" concept of feeling responsible for the maladies experienced by the less economically, educationally, and politically privileged individuals from traditionally oppressed groups is avoided. Instead, the concept of the status originating from a financial, educational, and/or country of origin privileges is emphasized to promote social collective consciousness based on responsibility and genuine preoccupation for the well-being of others. The principles of being part 
of a wealthier country and the individual responsibility for transforming and empowering others are instilled without the patronizing and condescending stigma.

(7) Full immersion in a different culture and linguistic environment allows students to experience cultural discomfort and cognitive dissonance that is conducive to cultural self-awareness. Consistently, the "luxury hotel" model is circumvented by providing room and board to the students in local establishments and family homes.

\section{Method}

\subsection{Study Research Questions}

This study was designed to qualitatively analyze student perceptions of their learning in an intensive faculty-led international course (IFLIC) by answering the following questions: (a) in which of the multicultural concepts do students self-report most learning?; (b) what are the mechanisms associated with learning of each multicultural concept?; (c) in which of the multicultural skills do students self-report most learning?; (d) what are the mechanisms associated with learning of each multicultural skill?; (e) which of the IFLIC curricular and instructional components do students report as most contributing to their learning?; (f) Which features of the above components are reported as most facilitating learning?

\subsection{Participant (Subject) Characteristics}

Twenty one participants represented diverse ages (ranging from young to mature adult), ethnicity (predominantly White/European descent, African American, and Asian American) and cultural backgrounds (e.g., five were bi/multilingual immigrants to the USA). Among the participants, 16 were monolingual English speakers, and only one visited the host country of the course prior to enrolling in the course.

\subsection{Sampling Procedures}

The participants were recruited on a voluntary basis from students enrolled in two intensive faculty-led multicultural counseling international courses (IFLIC) taught across two semesters by the second author.

\subsubsection{Sample Size, Power, and Precision}

A sample of 21 graduate students who attended urban or suburban campus of a private university located in a Midwest metropolitan area of the USA.

\subsubsection{Measures and Covariates}

The Post-trip Reflection and Evaluation Questionnaire (PREQ), a written semi-structured response instrument, was designed by the authors. The questionnaire was initially drafted based on an inductive analysis of the IFLIC syllabi and course documents (e.g., assignment handouts, instructor notes, readings) conducted by the first author. Subsequently, it was refined as a result of a series of interviews conducted by the first author with the second author, the instructor of the IFLIC courses. Finally, the questionnaire was triangulated in the process of the second author's review and revisions. The questionnaire required the participants to respond to the items first by rank ordering them according to a specific criterion (e.g., from most to least important) and then by writing a short answer to the open-ended questions.

\subsubsection{Research Design}

The participants were asked to respond to the individually to the PREQ. The responses were anonymous, and the questionnaire was administered during the IFLIC post-trip sessions by the first author who had no affiliation with the participants. All questionnaire responses to the open-ended questions were read separately by the first author and a graduate assistant (an advanced counselor education trainee). Subsequently, the inductive analysis and thematic representation methods were used as described below (Aurebach \& Silverstein, 2003). The two readers read all responses individually and later discussed their content to come up with a system of codes for each question and to cluster the codes into themes. Upon establishing the code system, the responses were classified into one of the codes independently by each reader. Only items with a minimum of two codes, each used at least twice to classify a response, were included in the results. All disagreements about coding of the responses were discussed by the raters until an agreement was reached, resulting in inter-rater agreement at $100 \%$ level.

\subsection{Experimental Manipulations or Interventions}

The intensive faculty-led international course (IFLIC) in this study provided the curriculum of the traditional on campus multicultural class using the same learning activities (i.e., in-class lectures, presentations, discussions) and assignments (i.e., formative and summative assessments) during the semester prior to the departing to the host country. The aforementioned curricular elements support the goals advocated by the accrediting bodies that promote the acquisition of cultural self-awareness, understanding of others, and multicultural skills. In addition to these goals, the course was designed to promote emotional and behavioral changes consistent with the pedagogical principles described above. In 
order to achieve these changes, the following specific components were integrated into curriculum. First, several international service learning activities were designed to allow students to provide a series of workshops and presentations tailored to serve the needs of various populations in local communities. For instance, presentations have been developed to equip local teachers with skills to cope with challenging students and those who have extensive emotional and psychological needs. Similarly, middle school students have received training on how to increase their self-esteem, maintain a healthy balance between school and personal lives, and how to strategize long-term career goals.

Secondly, visits to native cultural communities and events were arranged so that students have the opportunity to engage within several indigenous communities that have Mayan customs, ways of living, and different diets. Landmark locations are extensively explored and researched by the students before the actual visits take place. Thirdly, semi-structured interactions in local communities were designed for students to interact with some locals using sets of pre-determined questions as a guide for these interactions. The purpose of these interactions was for the students to explore the cross-cultural communication dynamics and experience similarities and differences among cultures.

The IFLIC in this study was delivered in Guatemala, a country located in Central America at the southern tip of Mexico (Encyclopedia of the Nations, 2015). Guatemala has area of 108,890 square kilometers (42,042 square miles) and shares land boundaries with Belize, Honduras, El Salvador, and Mexico. Guatemala City is the national capital and home to 2 million Guatemalans, mostly of mestizo/ladino descent. The fertility rate in Guatemala is the highest in Latin America, with an average of 5 children born to each Guatemalan woman during her lifetime. Fifty-eight percent of Guatemala population is concentrated in rural areas and connected to the large indigenous (Amerindian) groups. Individuals descending from the Mayan Indians account for $56 \%$ of the nation's total population, making Guatemala the Latin American nation with the largest indigenous population relative to total population. The remaining $44 \%$ of the population is mestizo that is of mixed Amerindian-Spanish descent (also called ladino in local Spanish). The country of Guatemala was chosen as a host country due to its intra-ethnic and cultural diversity accompanied with a complexity in linguistic variety (i.e., 22 native indigenous languages and Spanish). In addition, the authors have established collaborative institutional agreements between a local private university in Guatemala and their respective academic institutions in the U.S.A. to facilitate the delivery of the teaching and service learning activities.

Prior to delivering course content all students were administered the Miville-Guzman Universality Diversity Scale (MGUDS), a pre-course measure of openness to diversity (Swazo \& Celinska, 2014). Further, all students responded to the Multilingual Competence in Counselor Education and Allied Disciplines (MCCEAD), a survey designed by the second author to measure multicultural/multilingual experiences and competencies. Then, six pre-departure sessions were held on campus during the semester prior to leaving the U.S.A. to deliver the curriculum of the on campus multicultural course (e.g., interactive lectures, panels, and projects) (See Diagram 1 below).

In addition, students developed a culture genogram and "I as Cultural Being" statements to articulate their own personal ethnic/cultural identities and began journaling to reflect on their ongoing multicultural learning and personal growth. The international part of the course spanned 13 days and encompassed tours of villages and historical landmarks in the host country, as well as international service learning activities with children, adolescents, parents, teachers, and community leaders. At the end of the course, participants were administered the Post-trip Reflection and Evaluation Questionnaire (see the detailed description in the Method section) and the Miville-Guzman Universality Diversity Scale (MGUDS) to analyze course learning outcomes relative to multicultural competencies and openness to diversity, respectively, resulting from the international experience.

Finally, upon return from Guatemala, students wrote a cultural activity paper that described their application of multicultural competencies learned in the international context to a diversity experience in the U.S.A. and compiled journal entries for the entire course. These post-trip assessments along with the university's course evaluations framed summative post-course assessment in order to improve future course developments and deliveries. 


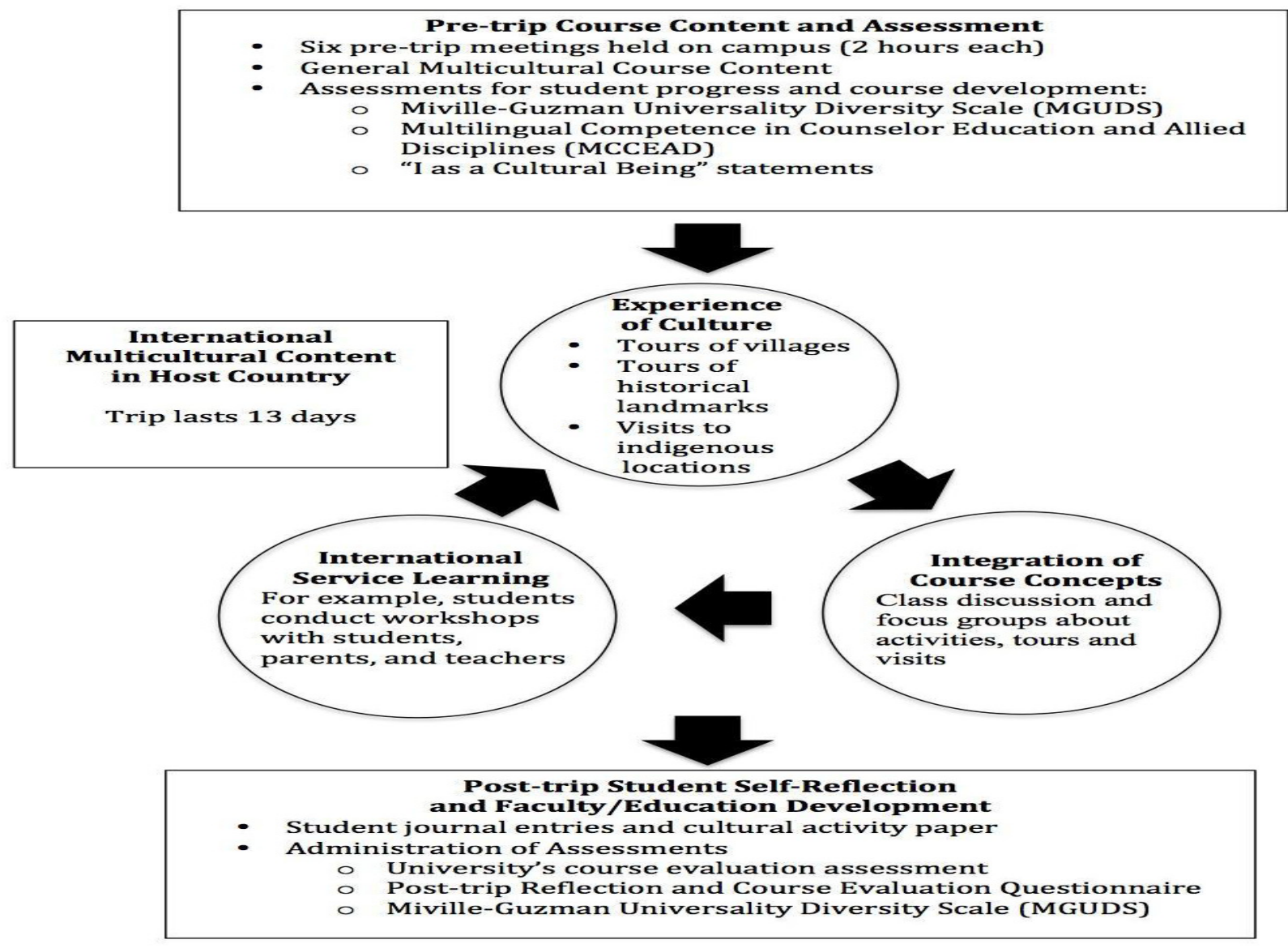

Figure 1. Course Development and Implementation

\section{Results}

\subsection{Recruitment}

The 21 graduate students who volunteered to participate in the study completed all measures as described above.

\subsection{Statistics and Data Analysis}

\subsubsection{Student Perceptions of Learning of Multicultural Concepts}

The participants were asked to rank order the five multicultural concepts targeted in the course in regards to the amount of their learning (from most to least). Next, the participants were asked to provide a short description of the process (mechanism) by which they achieved the reported outcomes. Table 1 shows the ranks of the five IFLIC multicultural concepts, along with the reported specific mechanisms associated with learning of each concept. Non-specific mechanisms of learning in the form of an overall increase of learning are not included in Table 1 but are discussed below.

Table 1. Ranks of the IFLIC multicultural concepts and associated learning mechanisms.

\begin{tabular}{|c|c|c|}
\hline Rank/ Multicultural concept & Specific mechanisms of learning a concept & $\begin{array}{l}\text { Percent of } \\
\text { responses }\end{array}$ \\
\hline \multirow{2}{*}{$\begin{array}{l}\text { 1/ Respect Towards Others who Differ } \\
\text { from Me }\end{array}$} & Becoming more open-minded & 31 \\
\hline & Relating respect to the ethics of care & 23 \\
\hline \multirow{2}{*}{$\begin{array}{l}\text { 2/ Understanding and Challenging Own } \\
\text { Cultural Worldview }\end{array}$} & Exploring own world view & 39 \\
\hline & Gaining new insights about own worldview & 17 \\
\hline \multirow[t]{2}{*}{ 3/ Understanding Human Diversity } & Acceptance and/or respect for an individual's uniqueness & 45 \\
\hline & Acquiring insights into diversity within cultures & 55 \\
\hline \multirow{2}{*}{$\begin{array}{l}\text { 4/ Understanding the Characteristics of } \\
\text { Diverse Groups }\end{array}$} & Understanding the complexity of diversity & 44 \\
\hline & Understanding the specifics of intragroup diversity & 19 \\
\hline \multirow[t]{2}{*}{ 5/ Understanding Social Advocacy } & Assuming personal responsibility & 38 \\
\hline & Acknowledging the importance of social advocacy & 31 \\
\hline
\end{tabular}

The students indicated most learning (the first ranking concept) in regards to "Respect Towards Others who Differ from Me". While the majority (46\%) of responses pointed out to an unspecific overall increase in learning, two specific 
mechanisms of increasing respect towards others were also indicated: becoming more open-minded $(31 \%)$ and relating respect to the ethics of care (23\%). Similarly, for the second ranking concept, "Understanding and Challenging Own Cultural Worldview", the majority (44\%) of responses were indicative of overall increase in awareness of own worldview. Among the remaining responses, $39 \%$ attributed self-growth to the mechanism of exploring own world view and $17 \%$ to gaining new insights about own worldview. In contrast, for the third ranking concept, "Understanding Human Diversity", all responses designated a specific learning mechanism, either by relating learning to gains in the overall acceptance and/or respect for an individual's uniqueness (45\%) or acquiring insights into diversity within cultures $(55 \%)$. Consistently, for the fourth ranking concept, "Understanding the Characteristics of Diverse Groups", the majority of responses (63\%) linked learning to a specific mechanism; $44 \%$ to gains in understanding the complexity of diversity and $19 \%$ to gains in the specifics of intragroup diversity. The remaining $38 \%$ of responses indicated increased understandings without specifying an underlying mechanism. Congruently, for the fifth ranking concept, "Understanding Social Advocacy", only $31 \%$ of responses indicated unspecific overall increase in learning while the remaining responses marked one of the two specific mechanisms of learning: assuming personal responsibility (38\%) or acknowledging the importance of social advocacy (31\%).

In conclusion, the students' perceptions of their learning of multicultural concepts suggest a pattern in which growth in concepts with most self-reported gains (i.e., highest ranking concepts) is attributed to an unspecific overall increased awareness of the concept's meaning. In contrast, the concepts with less self-reported learning were associated with multiple specific mechanisms that enabled learning. Perhaps, the unspecific overall increase in learning correlated with the most substantial conceptual growth was facilitated by multiple interrelated mechanisms that proved difficult for the students to dissect and describe.

\subsubsection{Student Perceptions of Learning of Multicultural Skills}

The participants were asked to rank order the nine multicultural skills targeted in the course relative to the amount of learning (from most to least) and later to describe their learning mechanism(s) that enabled the reported learning outcomes. Only responses to four of the targeted skills were included in the subsequent analysis because of the requirement of an item having a minimum of two codes, each code with at least two responses. Table 2 shows the ranks of the four IFLIC multicultural skills, along with the reported specific mechanisms associated with learning of each skill. Non-specific mechanisms of learning in the form of an overall increase of learning are not included in Table 2 but are discussed below.

Table 2. Ranks of the IFLIC multicultural skills and associated learning mechanisms.

\begin{tabular}{|c|c|c|}
\hline Rank/ Multicultural skill & Specific mechanisms of learning a skill & $\begin{array}{l}\text { Percent of } \\
\text { responses }\end{array}$ \\
\hline $\begin{array}{l}\text { 1/ Capacity to Comprehend the } \\
\text { Multicultural Reality of Diverse Clients }\end{array}$ & $\begin{array}{l}\text { Importance of gaining an understanding of a diverse } \\
\text { client's reality }\end{array}$ & 50 \\
\hline $\begin{array}{l}\text { 2/ Ability to Self-assess Biases and } \\
\text { Prejudices }\end{array}$ & $\begin{array}{l}\text { Opportunities to challenge their own biases } \\
\text { Reflection and new self-knowledge } \\
\text { Understanding of the importance of self-reflection }\end{array}$ & $\begin{array}{l}37 \\
37 \\
26\end{array}$ \\
\hline $\begin{array}{l}\text { 3/ Ability to Assess Clients in a } \\
\text { Non-biased Manner }\end{array}$ & $\begin{array}{l}\text { Increased knowledge of own bias } \\
\text { Opportunities to overcome own bias }\end{array}$ & $\begin{array}{l}43 \\
57\end{array}$ \\
\hline 4/ Understanding of Immigrant Clients & $\begin{array}{l}\text { Awareness of immigration as a cultural factor } \\
\text { Specific knowledge of immigrants }\end{array}$ & $\begin{array}{l}33 \\
66\end{array}$ \\
\hline
\end{tabular}

The students designated most learning (the first ranking skill) relative to "Capacity to Comprehend the Multicultural Reality of Diverse Clients". Whereas half of the responses pointed out to an unspecific overall increase in learning, another half related growth to the enhanced appreciation of the importance of gaining an understanding of a diverse client's reality. In contrast, for the second ranking skill, "Ability to Self-assess Biases and Prejudices", all responses attributed self-growth to a specific learning mechanism: $37 \%$ to opportunities to challenge their own biases, $37 \%$ to gains acquired through reflection and new self-knowledge, and $26 \%$ to newly gained understanding of the importance of self-reflection. Consistently, for the third ranking skill, "Ability to Assess Clients in a Non-biased Manner", all responses designated a specific learning mechanism, either by relating learning to the increased knowledge of own bias (43\%) or to the opportunities to overcome own bias relevant to the assessment process (57\%). Finally, for the fourth ranking skill, "Understanding of Immigrant Clients", all responses linked learning to a specific mechanism; 33\% to increased awareness of immigration as a cultural factor and $66 \%$ to gains in specific knowledge of immigrants.

In conclusion, the student's perceptions of their learning of multicultural skills indicate that they were able to relate their growth to multiple specific learning mechanisms. Based on the percentage of responses that designate a specific learning mechanism, it appears that the students' facility with self-analysis of acquiring new multicultural skills was superior to that of gaining new multicultural conceptual understandings. Perhaps, the more observable nature and the narrower scope 
of skills, as compared to concepts, allowed the student to capture and reflect on their learning in more precise manner.

\subsubsection{Student Perceptions of the Importance of the IFLIC Course Components}

The Post-trip Reflection and Evaluation Questionnaire prompted students to reflect on the importance of the IFLIC curricular and instructional components for acquiring their multicultural competencies. The IFLIC components were divided into: (1) General Multicultural Course Content (GMCC), taught in both the on campus and international formats, and (2) International Multicultural Course Content (IMCC), taught exclusively in international format. For both GMCC and IMCC, the participants were asked to rank order the components in regards to the amount of contribution to their learning (from most to least) and to follow up with a short description of the process (mechanism) by which each component contributed to the reported outcomes.

In regards to the GMCC, five of the six met the requirement of having at least two codes containing a minimum of two responses. Table 3 shows these components and their features reported as facilitating student learning.

Table 3. Ranks of the GMCC components and features associated with each component.

\begin{tabular}{|c|c|c|}
\hline Rank/ GMCC component & Features of each component & $\begin{array}{l}\text { Percent of } \\
\text { responses }\end{array}$ \\
\hline 1/ In-class Lectures, Presentations and & Conceptual depth & 47 \\
\hline \multirow[t]{2}{*}{ Discussions } & Connection to personal experience & 32 \\
\hline & Open-minded nature & 21 \\
\hline \multirow[t]{4}{*}{ 2/ Culture Genogram } & Opportunity to learn about self & 53 \\
\hline & Opportunity to learn about others & 18 \\
\hline & Relate it to the pre-trip self-image & 18 \\
\hline & Gain conceptual multicultural insights & 11 \\
\hline Out-of-class & Rehearsal of class content & 44 \\
\hline \multirow[t]{2}{*}{ Classmates } & Establishing interpersonal relations with classmates & 39 \\
\hline & Non-judgmental nature of self-expressions & 17 \\
\hline \multirow[t]{3}{*}{ 4/ Journaling } & Extension of in-class learning & 43 \\
\hline & Opportunity to reflect on self & 36 \\
\hline & Opportunity to reflect on the on-going experience & 21 \\
\hline \multirow[t]{3}{*}{ 5/ Cultural Activity Reaction Paper } & Learning about other cultures & 50 \\
\hline & Application of knowledge in community settings & 25 \\
\hline & Opportunity to extend own worldview & 25 \\
\hline
\end{tabular}

The students indicated "In-class Lectures, Presentations and Discussions" as the GMCC component that mostly contributed to their multicultural learning. In particular, $47 \%$ of responses related this contribution to its conceptual depth, $32 \%$ to its connection to personal experience, and $21 \%$ to its open-minded nature. For the second ranking GMCC component, "Culture Genogram", its contribution was attributed to the opportunities to learn about self (53\%), learn about others $(18 \%)$, relate it to the pre-trip self-image (18\%) and gain conceptual multicultural insights $(11 \%)$. For the third ranking GMCC component, "Out-of-class Discussions with Classmates", 44\% of the responses linked this component with the context of rehearsal of class content, $39 \%$ with establishing interpersonal relations with classmates, and $17 \%$ with the non-judgmental nature of self-expressions. Further, for the fourth ranking GMCC component, "Journaling", 43\% of responses related this component to the format that allowed an extension of in-class learning, $36 \%$ to an opportunity to reflect on self, and $21 \%$ to an opportunity to reflect on the on-going experience. Finally, for the fifth ranking GMCC component, "Cultural Activity Reaction Paper", 50\% of responses attributed its contribution to learning about other cultures, $25 \%$ to application of knowledge in community settings, and $25 \%$ to an opportunity to extend own worldview.

In general, the students' perceptions of the relative contribution of the GMCC course components suggest that the perceived value of these course pedagogical elements was associated with the following three factors: (1) multiple opportunities to extend multicultural knowledge and apply it to personal experiences, (2) situating learning in the context of non-judgmental and meaningful reflection on self and others, and (3) intellectual rigor of content.

In regards to IMCC, all four components were analyzed. Table 4 shows these components and their features reported as facilitating student learning. 
Table 4. Ranks of the IMCC components and features associated with each component.

\begin{tabular}{lll}
\hline Rank/ IMCC component & Features of each component & $\begin{array}{l}\text { Percent } \\
\text { responses }\end{array}$ \\
\hline 1/ Interactions/Experiences within Local & Experiential nature of learning & 50 \\
Communities & Connection to self-reflection & 25 \\
& Increased comfort with diversity & 25 \\
2/ Immersion in Non-English Speaking & Understandings of the cultural adaptation process & 64 \\
Country & Experiential nature of learning & 36 \\
& & 50 \\
3/ Service Learning Activities & Exposure to other cultures & 30 \\
& Acknowledgment of universality across cultures & 20 \\
4/ Field Trips and Tourist Destinations & Gaining new multicultural insights & 45 \\
& Opportunities to acquire new multicultural insights & 33 \\
\hline
\end{tabular}

The students designated "Interactions/Experiences within Local Communities" as the IMCC component that mostly contributed to their multicultural learning. In particular, $50 \%$ of responses related its contribution to the experiential nature of learning, $25 \%$ to its connection to self-reflection, and $25 \%$ to the outcome of increased comfort with diversity. For the second ranking IMCC component, "Immersion in Non-English Speaking Country", its contribution was attributed to either to the opportunities to gain understandings of the cultural adaptation process (64\%) or to the experiential nature of learning (36\%). Further, for the third ranking IMCC component, "Service Learning Activities", $50 \%$ of the responses linked this component with the exposure to other cultures, $30 \%$ with the acknowledgment of universality across cultures, and $20 \%$ with gaining new multicultural insights. Finally, for the fourth ranking IMCC component, "Field Trips and Tourist Destinations", $45 \%$ of responses related this component to the opportunities to acquire new multicultural insights, $33 \%$ to the experiential nature of learning, and $22 \%$ to the fact that field trips provided less intellectually demanding learning context.

In sum, the students' perceptions of the relative contribution of the IMCC course components pointed out that the perceived value of these course pedagogical elements was predominantly connected with experiential nature of learning and/or exposure to novel cultural circumstances that often lead to increased comfort with diversity and new multicultural insights.

\section{Discussion}

Intensive faculty-led international courses (IFLIC) are an alternative to the traditional on campus multicultural courses for students who want to embark in a more profound multicultural experience. The results of this study indicate that this course format provides meaningful and in-depth learning experiences not available through the traditional on campus format. Furthermore, the study findings call for a potential revamping of the way multiculturalism has been traditionally taught in counselor education programs and for a serious commitment of the profession to provoke change that transcends the classroom arena. The following are some conclusions and recommendations based on the current results that may assist faculty with preparation of an effective IFLIC to enhance the quality of delivery of multicultural principles in counselor education and similar programs:

1. The students self-reported increased competencies in both the foundational multicultural concepts as well as specific multicultural skills necessary to work with diverse populations. However, their ability to self-analyze the acquisition of skills appeared superior to their ability to self-analyze gains in conceptual understandings. Thus, an effective IFLIC design should be based on a curriculum that balances acquisition of knowledge and planning of culturally sensitive interventions, with particular attention to self-reflection on learning of more complex concepts. This can be achieved, for example, by providing pre- and/or post-trip instruction that explicitly facilitates application of the foundational multicultural concepts to culture-specific interventions.

2. Although most students indicated overall growth in multicultural concepts, some were unable to specify an underlying mechanism of these gains or attribute their overall increased awareness to any specific understandings. Consequently, students may need extensive and/or explicit faculty guidance to enhance their self-reflection in the process of acquiring multicultural concepts. For instance, faculty can create a list of pre-constructed journaling questions serving as a reflection compass and guide group discussion (e.g., focus groups) to facilitate deeper understandings of the multicultural learning processes.

3. When specifying the mechanisms underlying their learning, students predominantly point to: (a) exploring and challenging own pre-conceptions, (b) gaining new experiences that expanded their knowledge and awareness of diversity, (c) acquiring understandings of the complexity and contingencies of diversity, and (d) understanding and appreciation of the importance of multicultural competence and personal growth. Clearly, to maximize student outcomes, an effective 
IFLIC design should capitalize on these learning processes, preferably in the context of authentic interactions within a culture that extends the students' cultural comfort zones.

4. Among the General Multicultural Content Components (GMCC), students most valued the contributions of in-class structured activities such as lectures, presentations, and discussions. They attributed their importance to intellectual rigor and the non-judgmental context in which they occur. In the IFLIC format, these activities serve as a springboard for extended, out-of-class learning and reflection. It is through the extensive and meaningful exchanges with classmates within the context of off-campus shared living and experiences that students achieve broader and deeper understandings of multicultural concepts. Further, the perceived contribution of other GMCC components was additionally linked to the opportunities to extend multicultural knowledge and apply it to personal experiences, as well as to situating learning in the context of non-judgmental and meaningful reflection on self and others. Thus, it is important for faculty to maintain the rigor of in-class activities, connect them to personal cultural experiences, and utilize them as a framework for out-of-class peer mediated learning activities (e.g., discussion groups).

5. Among the International Multicultural Content Components (IMCC), students most value the contributions of their direct interactions within local communities and language immersion experiences. Because one of the most important features of these experiences relates to their experiential learning nature, it is imperative to design these experiences within the learning-by-doing framework. In addition, service learning activities were perceived by students as a valuable opportunity for extended cultural exposure and gaining insights into the universal nature of human experience. Consequently, an effective IFLIC design should incorporate a variety of service learning activities, preferably in the context that allows students to apply their professional skills in culturally novel situations.

6. To increase student multicultural learning outcomes, faculty should hold pre-trip and post-trip sessions that include guest lectures, group activities, and/or service learning activities. As a precursor to the international experience, it is also necessary that students understand that the purpose of traveling is to increase awareness of own assumptions, values, and biases, and understating of the worldview of the culturally different which ultimately lead to developing culturally appropriate interventions.

\section{References}

Auerbach, C. F., \& Silverstein, L. B. (2003). Qualitative data: An introduction to coding and analysis. New York: New York University Press.

Alexander, C. M., Krucek, T., \& Ponterotto, J. G. (2005). Building multicultural competencies in school counselor trainees: An international immersion experience. Counselor Education and Supervision, 44(4), 255-266. http://dx.doi.org/10.1002/j.1556-6978.2005.tb01754.x

Amir, Y. (1969). Contact hypothesis in ethnic relations. Psychological Bulletin, 71(5), 319-342. http://dx.doi.org/10.1037/h0027352

Amir, Y., \& Garti, C. (1977). Situational and personal influence on attitude change following ethnic contact. International Journal of Intercultural Relations, 1(2), 58-75. http://dx.doi.org/10.1016/0147-1767(77)90042-6

Annette, J. (2003). Service-learning internationally: Developing a global civil society. Billing \& J. Eyler (Eds.), Deconstructing service-learning: Research exploring context, participation and impacts (pp.43-62). Greenwich, CT: Information Age Publishing.

Arthur, N., \& Achenbach, K. (2002). Developing multicultural counseling competencies through experiential learning. Counselor Education and Supervision, 42(1), 2-14. http://dx.doi.org/10.1002/j.1556-6978.2002.tb01299.x

Baty, R. M., \& Dold, E. (1977). Cross-cultural homestays: An analysis of college students' responses after living in an unfamiliar culture. International Journal of Intercultural Relations, 1, 61-75. http://dx.doi.org/10.1016/0147-1767(77)90007-4

Bringle, R. G., \& Tonkin, H. (2004). International service-learning: A research agenda. H. Tonkin, S. J. Deeley, M. Pusch, D. Quiroga, M. J. Siegel, J. Whiteley, \& R. G. Bringle (Eds.), Service-learning across cultures: Promise and achievement (pp. 52-68). New York: International Partnership for Service-Learning and Leadership.

Chen, C. C., Jones, K. T., \& Moreland, K. (2014). Differences in learning styles. CPA Journal, 84(8), 46-51. http://dx.doi.org/10.1097/01.PAT.0000443503.70850.eb

Coleman, M. N. (2006). Critical incidents in multicultural training: An examination of student experiences. Journal of Multicultural Counseling and Development, 34, 168-182. http://dx.doi.org/10.1002/j.2161-1912.2006.tb00036.x

Collins, N. M., \& Pieterse, A. L. (2007). Critical incidents in multicultural training: An approach for developing active racial/cultural awareness. Journal of Counseling and Development, 85, 14-23. 
http://dx.doi.org/10.1002/j.1556-6678.2007.tb00439.x

Council for Accreditation of Counseling and Related Educational Programs [CACREP] (2009). 2009 standards for accreditation. Retrieved from http://www.cacrep.org/wp-content/uploads/2013/12/2009-Standards.pdf

Crabtree, R. D., \& Sapp, D. A. (2009). Realizing the university mission in partnership with Nicaragua: Internationalization, diversity, and social justice. In D. Starke-Meyerring \& H. Duin (Eds.), Designing global learning environments: Visionary partnerships, policies, and pedagogies (pp. 61-79). Rotterdam: Sense Publications.

Encyclopedia of the Nations (2015). Guatemalar Retrieved from http://www.nationsencyclopedia.com/economies/Americas/Guatemala.html\#ixzz3RwD9AExX

Estrada, A. U., Durlak, J. A., \& Juarez, S. C. (2002). Developing multicultural counseling competencies in undergraduate students. Journal of Multicultural Counseling and Development, 30,110-123. http://dx.doi.org/10.1002/j.2161-1912.2002.tb00483.x

Ibrahim, B. L. (2012). International service-learning as a path to global citizenship. J. A. Hatcher, R. G. Bringle, J. A. Hatcher, \& R. G. Bringle (Eds.), Understanding service-learning and community engagement: Crossing boundaries through research (pp. 11-21). Charlotte, NC: IAP Information Age Publishing.

Kerl, S. B. (2002). Using narrative approaches to teach multicultural counseling. Multicultural Counseling and Development, 30, 143-171. http://dx.doi.org/10.1002/j.2161-1912.2002.tb00485.x

Kiely, R. (2011). What international service learning research can learn from research on international learning? R. G. Bringle, J. A. Hatcher, \& S. G. Jones (Eds.), International service learning: Conceptual frameworks and research (pp. 243-273; IUPUI Series on Service Learning Research, Vol. 1). Sterling, VA: Stylus.

Kim, Y. Y. (1995). Cross-cultural adaptation: An integrative theory. In R. L. Wiseman (Ed.), Intercultural communication theory (pp. 91-109). California: Sage.

Parker, B., \& Dautof, D. A. (2007). Service-learning and study abroad: Synergistic learning opportunities. Michigan Journal of Community Service Learning, 13(2), 40-52.

Rowell, P. C., \& Benshoff, J. M. (2008). Using personal growth groups in multicultural counseling courses to foster students' ethnic identity development. Counselor Education and Supervision. 48(1), 2-15. http://dx.doi.org/10.1002/j.1556-6978.2008.tb00058.x

Stebnicki, M., \& Cubero, C. (2008). A content analysis of multicultural counseling syllabi from rehabilitation counseling programs. Rehabilitation Education, 22(2), 89-100. http://dx.doi.org/10.1891/088970108805059444

Swazo, R. (2013).The bilingual counselor's guide to Spanish: Basic vocabulary and interventions for the non-Spanish speaker. New York, NY: Routledge.

Swazo, R. \& Celinska, D. (2014). Cutting edge practices to teach multicultural competencies in counseling, psychology, and education: Teaching abroad or on campus? Intercultural Education, 25(2), 105-113. http://dx.doi.org/10.1080/14675986.2014.886821

This work is licensed under a Creative Commons Attribution 3.0 License. 